
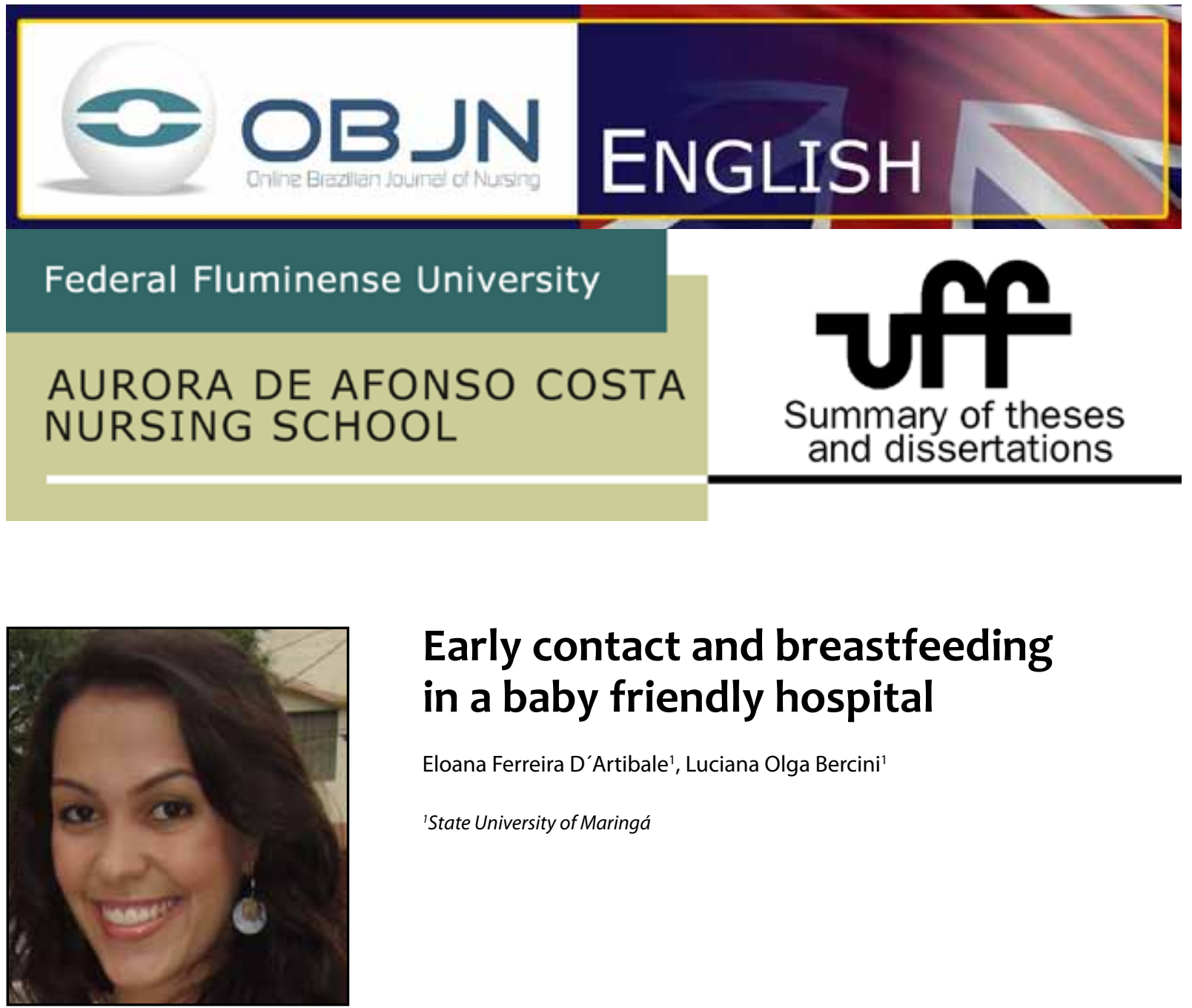

\title{
Early contact and breastfeeding in a baby friendly hospital
}

\author{
Eloana Ferreira D’Artibale', Luciana Olga Bercini \\ 'State University of Maringá
}

\section{ABSTRACT}

Aim: To analyze the experiences and meanings of early contact and breastfeeding of women, housed in a Baby Friendly Hospital, and the factors involved in these practices. Method:This was a descriptive, exploratory study in which we used a qualitative approach, conducted between November 2011 and January 2012, with 16 subjects. The data was submitted to content analysis and thematic modality.

Results: The approximation, between mother and child shortly after birth, provided a unique experience for women; with feelings and meanings favorable to mother-child bonding and the initiation of breastfeeding. The main obstacles, to the realization of the early contact and breastfeeding, were: the priority given to routine care after birth and the caesarean delivery.

Conclusion: In order to consolidate the fourth step, of the Baby Friendly Hospital Initiative, it was necessary to go beyond a purely technical approach; the approach ought to take into account the socio-cultural characteristics of patients; professionals; institutions; and society.

Keywords: Mother-Child Relations; Breast Feeding; Humanization of Assistance; Nursing 


\section{INTRODUCTION}

The Baby Friendly Hospital Initiative (BFHI) was conceived, in 1990, in order to increase the rates and benefits of breastfeeding. Hospitals, wishing to be accredited to the initiative, had to meet minimum global criteria; this was described as "Ten Steps to Successful Breastfeeding"(1).

Amongst the ten steps, we highlighted the fourth which stated that for at least an hour immediately after birth, the babies ought to be placed in skin to skin contact with their mothers and, offering help if needed ${ }^{(1)}$, the mothers encouraged to recognize when their babies were ready to be breastfed.

When the interaction between the pair was initiated soon after birth, there occurred the humanization and qualification of the assistance provided to women and newborns ${ }^{(2)}$. Therefore, early contact ought to be performed as soon as possible.

Often, rather than singular issues of women $^{(3.4)}$, the services and health professionals emphasized more practical and biological aspects of the contact and breastfeeding. However, with the puerperal woman being the agent of the referral process, it was essential to take into account her wishes and socio-cultural aspects.

Therefore, this study aimed to examine the experiences and meanings of early contact and breastfeeding of women, housed in a Baby Friendly Hospital, and the factors involved in such practices.

\section{METHOD}

This was a descriptive and exploratory study in which we used a qualitative approach. The participants were 16 women who were admitted for delivery at the University Hospital of Maringá and who were able to breastfeed and were able to establish contact, with their babies, shortly after birth. Data collection was conducted from November 2011 to January 2012, through a nonparticipating systematic observation of deliveries; daily field notes; and semi-structured interviews conducted after delivery. For the data treatment, we applied a thematic content analysis. Under Opinion No. $509 / 2009$, the State University of Maringá's Ethics Committee Involving Human Beings approved the study of.

\section{RESULTS}

It was observed that, despite the fact that the presence of a companion during childbirth was a practice experienced by few participants, it became a favorable factor for the realization of the fourth step.

The puerperal women were quite receptive to the completion of the fourth step; however, they presented little knowledge regarding this practice. In some instances, they showed that they were surprised and unprepared.

For the participants, the moment of early contact and breastfeeding was charged emotionally and, at times, difficult to describe. The time required, for the initiation of contact, was related to the priority given to routine care and caesarean delivery. This interfered negatively with the early contact and breastfeeding since they postponed this first meeting.

The study revealed, also, that the fourth step was not developed fully as recommended by the BFHI. However, there was a perception of intermediate practices since the contact, between mother and child, was still within the period described as "sensitive". This referred to the time, in which the newborns were more sensitive to tactile, thermal and odour stimuli, and the catecholamine levels were elevated; 
thus, facilitating the initiation of breastfee$\operatorname{ding}^{(5)}$.

The assistantial practice to delivery and the work process proved to be crucial in the characterization of assistance. These facilitated the visualization of the main barriers and pathways leading to the development and realization of the BFHI's fourth step the. Therefore, the survey data instigated the professionals' critical and reflective thoughts about the importance of changes in practices and knowledge which modulated attention in relation to the investigated phenomenon.

\section{CONCLUSION}

Based on this research's results, it could be stated that there was a long way to go in consolidating the fourth step. It was necessary to go beyond a purely technical approach since it involved the socio-cultural characteristics of specific patients; professionals; institutions; and society. In order to change such a reality, we had to invest in the discussion of ideas regarding BFHI. Above all, in order to initiate actions to implement the principles defended by this humanizing initiative of mother and child health care, we had to create opportunities for these ideas to be effective and to be experienced.

\section{REFERENCES}

1. Fundo das Nações Unidas para a Infância. Iniciativa Hospital Amigo da Criança: revista, atualizada e ampliada para o cuidado integrado: modulo 1: histórico e implementação. Brasília (DF): Ministério da Saúde; 2008.

2. Barbosa V, Orlandi FS, Dupas G, Beretta MIR, Fabbro MRC. Aleitamento materno na sala de parto: a vivência da puérpera. Cienc Cuid Saude. 2010; 9(2):366-73.

3. Soares RSS, Lessa PME, Pinheiro P, Damasceno A. Parturient's companion and their relationship with the nursing team: a qualitative study. Online Braz J Nurs [Internet]. 2010 June [Cited 2012 October 23]; 9(1). Available from: http://www. objnursing.uff.br/index.php/nursing/article/ view/2867

4. Strapasson MR, Fisher ANC, Bonilha ALL. Amamentação na primeira hora de vida em um hospital privado de Porto Alegre: relato de experiência. Rev Enferm UFSM. 2011; 1(3): 489-96.

5. Moore ER, Anderson GC. Randomized controlled trial of very early mother-infant skin-to-skin contact and breastfeeding status. J Midwifery Womens Health. 2007; 52(2):116-25.

Reference Bibliography: D'Artibale EF. O contato e a amamentação precoces no contexto de um Hospital Amigo da Criança. [Dissertação]. Maringá (PR), Brasil: Programa de Pós-Graduação em Enfermagem, Universidade Estadual de Maringá; 2012.

Thesis presentation date: September 27, 2012. Postgraduate Program in Nursing - State University of Maringá.

Board of examiners: Professor Luciana Olga Bercini (EMU); Professor Ana Lúcia de Lourenzi Bonilha (UFRGS); Professorleda Harumi Higarashi (UEM).

Mailing address: Avenida Andirá, 728 Centro - Doutor Camargo, PR, Brasil - CEP: 87155-000. E-mail: eloana_dartibale@hotmail.com

Received: 09/11/2012

Revised: 15/01/2013

Approved: 24/02/2013

Eloana Ferreira D'Artibale - Conception and design; data collection; interpretation and analysis; article writing; and final approval of the article.

Luciana Olga Bercini - Conception and design; data collection; interpretation and analysis; article writing; and final approval of the article. 